\title{
The effects of atmospheric currents on the migratory behavior of soaring birds: a review
}

\author{
Elham NOURANI ${ }^{\#}$ and Noriyuki M. YAMAGUCHI \\ Graduate School of Fisheries and Environmental Sciences, Nagasaki University, Bunkyo-machi 1-14, Nagasaki \\ 852-8521, Japan
}

\section{ORNITHOLOGICAL SCIENCE \\ (C) The Ornithological Society of Japan 2017}

\begin{abstract}
Atmospheric currents influence the choice of migratory routes and flight characteristics of birds as well as their decisions regarding migration onset and stopovers. Among long distance avian migrants, soaring birds are particularly dependent on wind and updrafts to help them complete their journeys. This review focuses on the behavioral adaptations of migratory soaring birds at various scales with regard to these atmospheric phenomena. Soaring landbirds and soaring seabirds have evolved morphological characteristics that make them specialists in soaring flight, thus enabling them to reduce the costs of migration significantly. We introduce the flight strategies of each group and discuss how migratory routes, flight characteristics, and onset and stopover decisions are all adjusted in relation to atmospheric conditions best suited for soaring. In addition, we discuss briefly how this strong dependence on atmospheric conditions makes soaring birds vulnerable to anthropogenic threats, such as wind energy development and climate change.
\end{abstract}

Key words Dynamic soaring, Migratory route, Raptors, Seabirds, Thermal soaring
Atmospheric conditions have considerable influence on various aspects of bird migration, such as migratory routes (Richardson 1976; Kranstauber et al. 2015), orientation (Richardson 1990a), flight characteristics (Alerstam 1979; Liechti \& Bruderer 1998), departure and stopover decisions (Liechti 2006), and intensity of migration (Richardson 1978). A bird's responses to local weather conditions affect the regional and seasonal efficiency of its migration, consequently impacting its reproductive success and population dynamics, thereby generating optimal migratory strategies through natural selection. Air movements (both horizontal and vertical) are particularly important in shaping the migratory behavior of birds. Horizontal winds are within the same order of magnitude as avian flight speeds. Therefore, winds that blow along the migratory track (tailwind) may increase flight speed (Liechti \& Bruderer 1998), while those blowing from the opposite direction (head wind) or from the side (side-wind or crosswind) may pose major obstacles to migratory movements by reducing ground speed, forcing deviation

(Received 13 June 2016; Accepted 19 November 2016)

\# Corresponding author, E-mail: mahle68@gmail.com from the intended flight direction, or temporarily halting migration.

While horizontal winds impact all avian migrants regardless of their phylogeny and morphology (Liechti 2006), changes in vertical air movement particularly impact soaring birds, as for them vertical air movements are essential and indispensable facilitators of migration. The vertical air movements that allow birds to gain height while using little energy, are generated by two major phenomena: the upward deflection of horizontal winds against tall structures, topographic features, or waves (i.e. orographic updrafts); and localized columns of rising air generated as the sun warms the Earth's surface during the day (i.e. thermals).

Soaring flight, also known as soaring-gliding flight, refers to the ability of birds to use atmospheric currents in order to sustain long periods of flight without flapping their wings, which is the most energetically cost-efficient form of flight (Kerlinger 1989; Hedenström 1993; Pennycuick 1998). Birds soar in upward moving air to gain altitude without spending much energy and complement it with gliding toward their preferred direction. Many large birds depend on soaring flight for their long-distance 
migratory movements, as they cannot accumulate enough fat reserves to fuel long periods of flapping flight (Smith et al. 1986; Watanabe 2016). Examples include seabirds (mostly Procellariiformes) as well as birds that fly predominantly over landmasses and inland water bodies (hereafter landbirds), particularly raptors (Accipitridae, Pandionidae, Falconidae and Cathartidae), storks (Ciconiidae), pelicans (Pelecanidae), anhingas (Anhingidae), and to some extent cranes (Gruidae), herons (Ardeidae), and bee-eaters (Meropidae). Passerines, such as the Common Starling Sturnus vulgaris, also occasionally engage in soaring flight (Cone 1968).

Various reviews have dealt with the effects of atmospheric conditions, particularly horizontal wind, on migratory birds (Richardson 1978; Richardson 1990a, 1990b, 1991; Liechti 2006). A decade has passed since the latest review (Liechti 2006), and a wide range of research has been conducted taking advantage of recent advances in telemetry devices (Robinson et al. 2010; Kays et al. 2015), wider availability of weather data (Kemp et al. 2012; Dodge et al. 2013), and the increasing use of modeling techniques (van Loon et al. 2011; Bauer \& Klaassen 2013; Kranstauber et al. 2015). In this review, we bring together studies on the effects of atmospheric currents on migratory birds, but focus on those that have investigated behavioral adaptations of soaring migrants with regard to horizontal and vertical air movements. In each section of this paper, we discuss a different aspect of the migratory behavior of soaring birds, addressing landbirds and seabirds separately. In a concluding section, we briefly summarize the major weather-related anthropogenic changes and developments that may threaten these particular birds in the future.

\section{FLIGHT STRATEGIES}

\section{1) Landbirds}

The adaptation of migratory birds to specific flight types is determined by biometrical and ecological constraints (Hedenström 1993; Spaar 1997). Soaring flight is the result of such adaptations in heavier birds with high wing loading (ratio of body mass to wing area), for which the energetic cost of flapping flight is extremely high. The wing morphology of such birds has evolved in such a way as to utilize atmospheric currents very efficiently for soaring and gliding with little cost.

The soaring landbirds include both obligate and facultative species. On the one hand, obligate soarers are the larger and heavier species, with long, broad wings; they depend solely on soaring flight in order to conserve as much energy as possible during long flights (Spaar 1997). These heavy birds have relatively high wing-loading and thus circle thermals slowly and are confined to using only strong thermals and particularly the stronger parts of each thermal, but have the advantage of being able to glide quickly from one thermal to the next (Shamoun-Baranes et al. 2003a). On the other hand, facultative soarers are lighter and have long, slender wings; they can alternate between soaring and flapping flight depending on air movements. These birds have relatively lower wing-loading, thus although they can climb thermals quickly and even use weak thermals, their gliding speed between thermals is limited. Although both obligate and facultative groups migrate diurnally, when thermals are formed, the latter commence travelling earlier in the day by depending on flapping flight, whereas the former must wait until several hours after sunrise for strong thermals to form (Kerlinger \& Gauthreaux Jr 1985; Bruderer et al. 1994; Spaar \& Bruderer 1997).

The family Accipitridae is the largest group of soaring landbirds and is therefore the main focus of the sections on landbirds in this review. Owing to the previously mentioned aspects of their morphology, members of the Accipitridae have varying migration tendencies with respect to updrafts, thermals, and wind. Among them, the most dependent on soaring flight, in order from obligate to facultative, are vultures (e.g. Gyps spp.) and eagles (e.g. Aquila spp.), hawks (Buteo spp.), kites (Milvus spp.), hawks (Accipiter spp.) and honey-buzzards (Pernis spp.), and finally harriers (Circus spp.) and ospreys (Pandion spp.) (Newton 2008).

Species in the family Falconidae also soar, but among raptors they are the least dependent on soaring flight. Their long pointed wings have high aspect ratios (wing span squared, divided by wing area) that generate low induced drag and consequently their energetic cost of flapping flight is low (Kerlinger 1985).

Soaring over land is achieved through the use of thermals or orographic updrafts (Fig. 1). Thermal soaring migrants gain height while circling in one thermal, then lose height while gliding to the next, repeating this process multiple times along their route (Newton 2008). In contrast, slope soaring requires orographic updraft (also known as deflection updraft; 


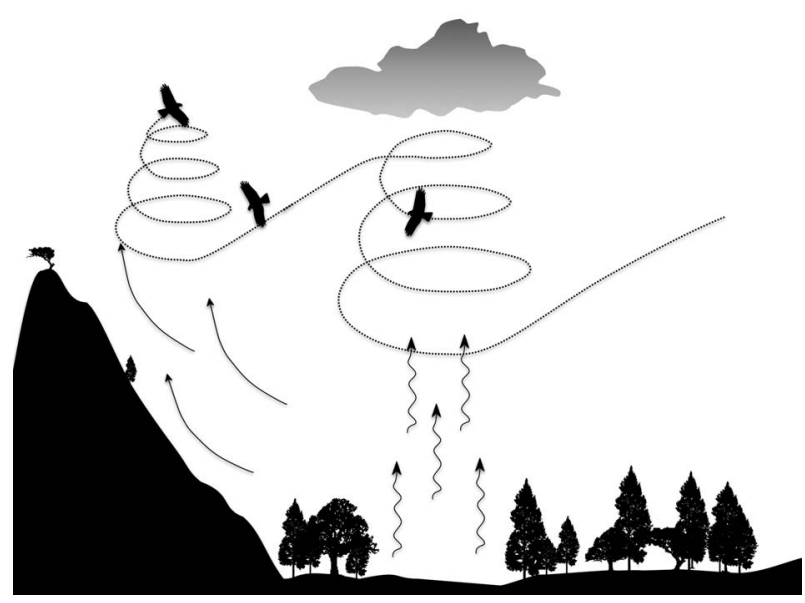

Fig. 1. Soaring flight in landbirds. Landbirds use two soaring modes interchangeably: thermal soaring (right) is facilitated by columns of rising warm air, i.e. thermals, and orographic soaring (left) on updrafts created by upward deflection of horizontal winds.

Bildstein 2006). Soaring landbirds can use both these types of soaring flight interchangeably, but slope soaring is a common mode of flight in the Americas, where most mountain ranges are aligned along a north-to-south axis and where strong orographic updrafts form thermal streets. Contorted soaring is a third type of soaring flight used frequently by vultures to subsidize flight, particularly in terrain where there are few thermal and orographic updrafts. Contorted soaring depends on shear-induced turbulence caused when horizontal air flow is interrupted by forest or tree line (Mallon et al. 2015).

The predominant flight type used by migratory birds is determined not only by their body mass and wing morphology, but also by their long-distance flight strategy in terms of optimizing their migration by energy or time minimization criteria. Although many avian species may be morphologically capable of adopting soaring flight, for many, particularly smaller species, the slow cross-country speed of such flight makes it unattractive for those birds aiming at maximizing their overall migration speed (Hedenström 1993).

\section{2) Seabirds}

Seabirds can be classified into four major groups based on their flight type: soarer-gliders (small albatrosses and large gadfly petrels), flap-gliders (surfacefeeding Procellariiformes and small gadfly petrels), glide-flappers (diving and Manx-type shearwaters and storm petrels), and flappers (Charadriiformes,
Alcidae and cormorants (Phalacrocoracidae)) (Spear \& Ainley 1997a). The flight pattern of each species is determined mostly by biometric characteristics; heavier birds with higher wing-loading and aspect ratio perform more soaring flight and lighter birds use a gradient of soaring and flapping flight (Alerstam et al. 1993).

Seabirds use atmospheric currents differently from landbirds in order to achieve low cost flight. Over land, soaring flight predominantly depends on thermals, but strong thermals are usually not generated over the sea surface. The exception to this occurs in the trade-wind zone $\left(5-30^{\circ} \mathrm{N}\right.$ and $\mathrm{S}$ of the equator) where strong "sea thermals" form throughout the year (Augstein 1980). The Magnificent Frigatebird Fregata magnificens has a restricted range within the trade-wind zone where it utilizes a thermal soaring strategy similar to that of landbirds (Weimerskirch et al. 2003; Weimerskirch et al. 2016).

Winds blow more strongly over the sea surface than over land and they become stronger with elevation due to reduced friction. Such strong winds facilitate two types of soaring flight: dynamic soaring and wave-slope soaring (Sachs 2005; Richardson 2015). Dynamic soaring is also known as wind-shear soaring (Richardson 2011) and gust soaring is a special case (Pennycuick 2002). The basis of dynamic soaring lies in the difference between the wind speed close to the sea surface and that above the windshear boundary, where friction is not a limiting factor (Richardson 2011). To start one cycle of dynamic soaring, a seabird flies upwind against the weak surface wind gaining height, it then flies above the wind shear, makes a downwind turn and angles its body to maximize the surface area affected by the wind and allows itself to be carried forward at speed (Fig. 2).

In wave-slope soaring, seabirds soar using any updraft derived from wind-wave interactions (similar to orographic updrafts forming along slopes on land). This behavior is particularly common among albatrosses (e.g. Diomedia spp.) and to a lesser extent in giant petrels Macronectes halli and M. giganteus) (Pennycuick 1982; Alerstam et al. 1993). Soaring conditions over the sea are generally improved when swell waves (i.e. waves not created by local wind) propagate upwind, as the wind flowing up the wave face creates a substantial updraft. Moreover, a swell wave propagating downwind with higher speed than the local wind can also produce a similar effect (Sullivan et al. 2008; Richardson 2011). These modes of soaring restrict seabirds to flying at much lower 


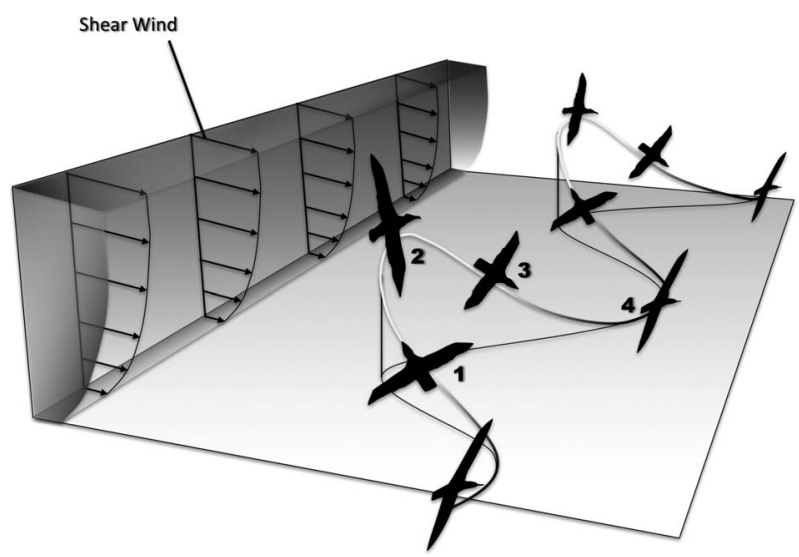

Fig. 2. Dynamic soaring in a seabird. One cycle of dynamic soaring begins as a seabird flies upwind, pulling up above the wind-shear layer (1), then encounters a strong gust of wind that allows the bird to increase its airspeed and gain kinetic energy. The bird then banks and turns (2) and descends downwind, flying in the opposite direction, descending back below the wind-shear layer with tailwind support (3), gaining another pulse of kinetic energy. The bird then turns and changes its direction to start the next cycle (4) (Sachs 2005; Richardson 2011).

elevations (Adams \& Flora 2010) than soaring landbirds that gain high altitude by circling in thermals.

A combination of dynamic soaring and wave-slope soaring is considered ideal for seabirds in order that they may maximize total energy gain. The energy demand of soaring is almost as low as that expended when sitting on the sea surface (Bevan et al. 1995; Weimerskirch et al. 2000). The low energy demand of soaring allows seabirds to perform some of the most impressive avian movements, both during the breeding season, when their foraging trips sometimes exceed thousands of kilometers (Phalan et al. 2007; MacLeod et al. 2008; Sachs et al. 2012), and on their long-distance trans-oceanic migrations (Spear \& Ainley 1999; Croxall et al. 2005; Shaffer et al. 2006).

\section{MIGRATORY ROUTE SELECTION}

\section{1) Landbirds}

Avian migrants do not follow the shortest great circle path between their breeding and wintering grounds. In fact, the large-scale movement of birds, particularly on migration, is determined mainly by patterns of air movement in the boundary layer. Air currents shape the most efficient flyways for birds in general (Kranstauber et al. 2015) and for soaring birds in particular (Vansteelant et al. in press). Although many soaring landbirds generally migrate on a broad front for parts of their migration, their flyways are shaped along topographical features that support the formation of strong thermals and orographic updrafts (Kerlinger 1989; Bildstein 2006; Newton 2008) such as mountain ranges, narrow valleys, and coastal plains, also along thermal streets (Pennycuick 1998) or seabreeze fronts (Alpert et al. 2000). The dependence of soaring birds on updraft and wind conditions is so strong that these variables can be used to predict and simulate their potential migratory routes (Brandes \& Ombalski 2004; Ainslie et al. 2014; Dennhardt et al. 2015). Major corridors for raptor migration for example, include the Appalachian Mountains, the Rocky Mountains, the Sierra Madre Oriental, the Talamanca Mountains, and the Andes in the Americas, the Alps in Europe, the Tien Shan and Hindu Kush and the southern Himalayas in Asia, and the escarpments of the Great Rift Valley in East Africa and the Middle East (Bildstein 2006).

Large water bodies act as ecological barriers along the migration route of many soaring birds (Alerstam 2001). Whether a species adopts watercrossing behavior or not is determined by its energy consumption during flapping flight (Agostini et al. 2015). Thermals are weak or absent over water, making soaring flight energetically inefficient or even impossible for soaring birds, particularly obligate soaring species that cannot accumulate enough fat reserves to sustain flapping flight to cross water bodies. Behavioral adaptation of these species favors avoidance of water crossing by taking detours over land and crossing water bodies only at their narrowest parts, such as straits, which may be considered migration "bottlenecks". Concentrations of many thousands of migrants can be seen at such "bottlenecks" including Costa Rica, Mexico and Panama in the Americas, Falsterbo, Organbidexka, and Gibraltar in Western Europe, Burgas and Bosphorus in Eastern Europe, Batumi and Himalayas in Central Asia and Malay Peninsula and Tsushima Strait in eastern Asia (Bildstein 2006).

While soaring migrants avoid flying over water where possible, migratory trajectories of some soaring birds include considerable water-crossings of various lengths. Most soaring birds that make such crossings are highly dependent on tailwind support (Meyer et al. 2000; Agostini et al. 2002; Agostini et al. 2004; Nourani et al. 2016) and possibly sea thermals in the trade-wind zone in East Asia (Bildstein 2006; Yamaguchi et al. 2012). Falconidae species, 
including Eleonora's Falcon Falco eleonorae, Sooty Falcon F. concolor and Amur Falcon F. amurensis, which fly long distances over water, also depend on tailwind assistance (Dixon et al. 2011; Mellone et al. 2011; Javed et al. 2012; Mellone et al. 2013).

\section{2) Seabirds}

The absence of physical barriers over the seas and oceans results in constant wind flows, providing ideal conditions for soaring flight. Although it has long been suggested that wind is important during the migration and at-sea movement of seabirds (Alerstam 1990; Spear \& Ainley 1999), until recently, the evidence of the role of wind patterns in shaping the migratory routes of seabirds was no more than speculation based on global wind patterns and indirect evidence from the migratory movements of certain species. With advances in tracking technology, it became possible for researchers to study the details of the migratory movements of seabirds, and to reveal their astonishing journeys of tens of thousands of kilometers, facilitated by atmospheric conditions, especially wind (Shaffer et al. 2006; González-Solís et al. 2007; Adams \& Flora 2010; Weimerskirch et al. 2015).

In both the Atlantic and the Pacific oceans, transequatorial migrants, including shearwaters, follow general flyways that resemble a figure-eight pattern (Shaffer et al. 2006; González-Solís et al. 2007), indicating that they travel in the direction of the prevailing winds, which circulate clockwise in the Northern Hemisphere and counter-clockwise in the Southern Hemisphere. Felicísimo et al. (2008) were among the first to explore the role of wind in the spatial and temporal patterns of movements of a migratory seabird (Cory's Shearwater Calonectris borealis), and explain why seabird migration routes are usually longer than the great circle routes connecting their departure and arrival points. Felicísimo et al. (2008) found that large-scale migration patterns are driven by spatiotemporal variations in the wind. Calms or strong headwinds resemble a barrier across a transoceanic path. González-Solís et al. (2009) further investigated the effects of wind on the migratory routes of soaring seabirds, and found that shearwaters followed low-cost pathways that were $26-52 \%$ longer than the shortest distance path. Their findings proved that 'wind highways' exist even for seabirds that migrate over topographically barrier-free oceans. These studies (Felicísimo et al. 2008; González-Solís et al. 2009) suggest that the optimum migration route for shearwaters is a compromise between wind-medi- ated costs and traveling time, perfected as they gain experience about choosing the best route.

The Wandering Albatross Diomedea exulans also avoids headwinds by circumnavigating Antarctica during the non-breeding period, essentially making a $10,000 \mathrm{~km}$ detour so as to continuously follow westerly winds. In addition to their migratory route, the migration range of albatrosses is also restricted by wind conditions (Weimerskirch et al. 2012).

\section{LOCAL-SCALE MIGRATORY BEHAVIOR}

\section{1) Landbirds}

Atmospheric conditions not only significantly influence the large-scale migratory patterns of soaring birds, but also affect their flight characteristics and decision-making at the local-scale. Soaring birds on migration adjust the timing of departure and stopover, as well as flight characteristics including altitude, speed, and direction, in response to changes in atmospheric conditions.

Although the timing of migration is under strong endogenous control (Gwinner 1996), weather is one of the major exogenous factors that trigger the onset of migration in birds (Richardson 1978; Liechti \& Bruderer 1998). Shamoun-Baranes et al. (2006) showed that obligate soaring birds, such as the Lesser Spotted Eagle Clanga pomarina, are more likely to be detained in their breeding range when soaring conditions are poor. Vansteelant et al. (2014) investigated local aggregations of raptors in the Black Sea coastal convergence zone and found that as cloud conditions limited thermal formation, obligate soaring birds aggregated near the coast and avoided taking off. Consequently, weather factors can be used to predict the density of migrating birds at migratory raptor watch sites (Richardson 1978; Yates et al. 2001).

Once soaring birds take off and commence migrating, they adjust their flight characteristics according to the quality and availability of updrafts. Flight altitude, for example, is adjusted in relation to intensity and depth of thermals (Shamoun-Baranes et al. 2003a). Soaring birds gain higher altitude until midafternoon when thermals are strongest, taking advantage of the opportunity to climb higher over a shorter period of time (Kerlinger \& Gauthreaux 1985; Spaar 1997).

Better convective conditions allow soaring birds to travel faster and farther (Shamoun-Baranes et al. 2003b; Mandel et al. 2008; Chevallier et al. 2010; 
Vansteelant et al. 2015). Lanzone et al. (2012) suggest that soaring birds are able to minimize their energy expenditure by switching between modes of soaring. For example, as wind speed increases and reduces thermal formation, Golden Eagles Aquila chrysaetos fly lower and use less vertical air space, in order to use more orographic uplift. Such adjustments allow for migration over longer periods each day (Katzner et al. 2015), increasing the overall speed of migration. Soaring birds also adjust their gliding airspeed to soaring conditions, actively reducing speed when thermals are scarce in order to avoid switching to flapping flight when possible (Horvitz et al. 2014). Sapir et al. (2011) studied the effects of convective conditions on the flight mode of the European Beeeater Merops apiaster using turbulent kinetic energy (TKE) levels as an index of thermal strength, and found that these facultative soaring birds switch between flapping flight at lower TKE levels and soaring flight at higher TKE levels.

Tailwind support may significantly affect the daily distances that birds travel (Chevallier et al. 2010; Mellone et al. 2012; Mellone et al. 2015). Against headwinds, obligate soarers are more affected than facultative soarers, as it is more difficult for them to switch to flapping flight to compensate for wind drift (Thorup et al. 2003; Limiñana et al. 2013; Vansteelant et al. 2015). Soaring birds also avoid unsuitable weather events such as dust storms by changing their flight direction and taking detours (Vansteelant et al. 2015). Even so, Turkey Vultures Cathartes aura have a remarkable ability to soar even under turbulent winds conditions, perhaps related to their dihedral wing profile and their use of contorted soaring (Mandel et al. 2008; Mallon et al. 2015).

Stopover decisions by soaring migrants are also influenced by weather conditions. Unfavorable atmospheric conditions can halt the migration of soaring birds. For example, White Storks Ciconia ciconia, pause during migration making rest stops when thermal conditions are weak, especially during the mornings and evenings (Berthold 2001). Similarly, migrating Golden Eagles, when they face no time limits during migration (pre-adult movements in spring and all movements in autumn) pause along their route so as to avoid suboptimal flight conditions (Duerr et al. 2015).

\section{2) Seabirds}

Soaring seabirds are also affected by local atmospheric conditions during migration. Since their soar- ing behavior is facilitated by wind, both the flight altitude and behavior of seabirds change as a function of wind speed and direction (Ainley et al. 2015). By analyzing simultaneous data from fine-scale wind conditions and aerial movements of Cory's Shearwaters, Felicísimo et al. (2008) showed that the shearwaters make local-scale decisions about flight direction based on wind conditions to achieve low-cost flight. It has been suggested that shearwaters adjust the time of crossing the equator in order to avoid the monsoon westerlies during the summer months (Felicísimo et al. 2008).

Wind direction also plays a key role in small-scale adjustments to flight direction. Soaring Procellariformes not only prefer crosswinds because they facilitate dynamic soaring (Alerstam et al. 1993; Spear \& Ainley 1997b), but also travel most frequently in crossing tailwinds and generally avoided headwinds (Adams \& Flora 2010). Additionally, Mateos \& Arroyo (2011) analyzed the off-shore distances of the most abundant species passing through the Strait of Gibraltar during spring and autumn and found that seabirds approached the coast in response to headwinds, indicating that wind direction and speed covaried with local patterns of flight trajectories.

Such decision-making by soaring seabirds is not only dependent on wind conditions however, as the birds alternate migratory flight with rest periods for refueling (Dias et al. 2011; Dias et al. 2012). Such behavior indicates that, especially when not crossing ecological barriers, soaring seabirds choose their local flight characteristics not only according to the most favorable winds, but also by considering the location of foraging areas. When encountering severe weather conditions, however, birds prefer to avoid such areas by circumnavigating them (Adams \& Flora 2010).

\section{FUTURE PERSPECTIVES}

The dependence of soaring birds on atmospheric conditions means that they are at risk from anthropogenic changes and developments. Two of the main areas of concern for future conservation of soaring birds include the development of wind energy facilities and climate change.

The existing and planned wind power generating facilities are all located in regions with strong winds. On-shore wind turbines are often arranged along coasts or mountain ridges, features that are used for lift by soaring birds (Barrios \& Rodríguez 
2004; Madders \& Whitfield 2006). These structures put soaring birds at risk of displacement and mortality (Drewitt \& Langston 2006; Kuvlesky et al. 2007). Depending on species- and site-specific attributes, different species of soaring birds have different levels of vulnerability to wind energy structures (Barrios \& Rodríguez 2004; Kuvlesky et al. 2007; Dahl et al. 2013; Villegas-Patraca et al. 2014; Ainley et al. 2015). Although avoidance of wind farms by changing migration trajectories has been observed among raptors (de Lucas et al. 2004; Cabrera-Cruz \& Villegas-Patraca 2016), adjustments in flight trajectories require deviating from the traditional optimal routes, consequently forcing the birds into conditions that require extra energy expenditure. Off-shore wind farms may have similar negative effects not only on migrating seabirds (Bradbury et al. 2014), but also on soaring landbirds that perform water-crossings.

Another anthropogenic phenomenon that may pose a threat to soaring birds (by altering their preferred atmospheric conditions) is global climate change. Global warming is expected to affect the dominant wind patterns, both in strength and direction. Existing literature on the consequences of such changes are mostly limited to the behavior of birds during the breeding season. Weimerskirch et al. (2012) showed that in response to the increased intensity of westerly winds in the Southern Ocean, Wandering Albatrosses have shifted their foraging range poleward. Thorne et al. (2016) investigated the effects of changes in wind patterns due to El Niño Southern Oscillation (ENSO) on incubating and brooding albatrosses and found that changes in wind speeds during El Niño and La Niña conditions affected habitat accessibility and travel costs for the birds. Climate change-induced alterations in wind conditions may also adversely affect soaring birds outside their breeding season, as their migration routes are determined largely by atmospheric currents. Changes in wind and updraft conditions may impact the ability of birds to use traditional routes; however, to our knowledge, the consequences of such changes on migrating birds have rarely been studied. Simulation models using projected values for weather variables will be helpful tools facilitating our understanding of the likely effects of climate change on avian migratory movements.

\section{ACKNOWLEDGMENTS}

We would like to thank Daniel N. Suzuki for pre- paring the figures and Wouter Vansteelant and an anonymous reviewer for their valuable comments on an earlier version of this review.

\section{REFERENCES}

Adams J \& Flora S (2010) Correlating seabird movements with ocean winds: linking satellite telemetry with ocean scatterometry. Mar Biol 157: 915-929.

Agostini N, Baghino L, Coleiro C, Corbi F \& Premuda G (2002) Circuitous autumn migration in the Shorttoed Eagle (Circaetus gallicus). J Raptor Res 36: 111-114.

Agostini N, Premuda G, Mellone U, Panuccio M, Logozzo D, Bassi E et al. (2004) Crossing the sea en route to Africa: autumn migration of some Accipitriformes over two Central Mediterranean islands. Ring 26: 71.

Agostini N, Panuccio M \& Pasquaretta C (2015) Morphology, flight performance, and water crossing tendencies of Afro-Palearctic raptors during migration. Curr Zool 61: 951-958.

Ainley DG, Porzig E, Zajanc D \& Spear LB (2015) Seabird flight behavior and height in response to altered wind strength and direction. Mar Ornithol 43: 25-36.

Ainslie B, Alexander N, Johnston N, Bradley J, Pomeroy A, Jackson P et al. (2014) Predicting spatial patterns of eagle migration using a mesoscale atmospheric model: a case study associated with a mountain-ridge wind development. Int J Biometeorol 58: 17-30.

Alerstam T (1979) Wind as selective agent in bird migration. Ornis Scand 10: 76-93.

Alerstam T (1990) Bird Migration. Cambridge University Press, Cambridge.

Alerstam T (2001) Detours in bird migration. J Theor Biol 209: 319-331.

Alerstam T, Gudmundsson GA \& Larsson B (1993) Flight tracks and speeds of Antarctic and Atlantic seabirds: radar and optical measurements. Phil Trans R Soc B 340: 55-67.

Alpert P, Tannhauser D, Leshem Y, Kravitz A \& Rabinovitch-Hadar M (2000) Migrating soaring birds align along sea-breeze fronts; first evidence from Israel. B Am Meteorol Soc 81: 1599-1601.

Augstein E (1980) The atmospheric boundary layer over tropical oceans. In: Shaw DB (ed) Meteorology over the tropical ocean. pp 623-624. Royal Meteorological Society, Bracknell.

Barrios L \& Rodríguez A (2004) Behavioural and environmental correlates of soaring-bird mortality at onshore wind turbines. J Appl Ecol 41: 72-81.

Bauer S \& Klaassen M (2013) Mechanistic models of animal migration behaviour - their diversity, struc- 
ture and use. J Anim Ecol 82: 498-508.

Berthold P (2001) Bird migration: a general survey. Oxford University Press, Oxford.

Bevan RM, Butler PJ, Woakes AJ \& Prince PA (1995) The energy expenditure of free-ranging black-browed albatrosses. Phil Trans R Soc B 350: 119-131.

Bildstein KL (2006) Migrating raptors of the world: Their ecology and conservation. Cornell University Press, Ithaca.

Bradbury G, Trinder M, Furness B, Banks AN, Caldow RWG \& Hume D (2014) Mapping seabird sensitivity to offshore wind farms. PLOS ONE 9: e106366.

Brandes D \& Ombalski D (2004) Modeling raptor migration pathways using a fluid-flow analogy. J Raptor Res 38: 195-207.

Bruderer B, Blitzblau S \& Peter D (1994) Migration and flight behaviour of Honey Buzzards Pernis apivorus in southern Israel observed by radar. Ardea 82: $111-122$.

Cabrera-Cruz SA \& Villegas-Patraca R (2016) Response of migrating raptors to an increasing number of wind farms. J Appl Ecol 53: 1667-1675.

Chevallier D, Handrich Y, Georges J-Y, Baillon F, Brossault P, Aurouet A et al. (2010) Influence of weather conditions on the flight of migrating black storks. P R Soc B-Biol Sci 277: 2755-2764.

Cone CD (1968) Thermal soaring by migrating starlings. Auk 85: 19-23.

Croxall JP, Silk JRD, Phillips RA, Afanasyev V \& Briggs DR (2005) Global circumnavigations: tracking year-round ranges of nonbreeding albatrosses. Science 307: 249-250.

Dahl EL, May R, Hoel PL, Bevanger K, Pedersen HC, Røskaft E et al. (2013) White-tailed eagles (Haliaeetus albicilla) at the Smøla wind-power plant, Central Norway, lack behavioral flight responses to wind turbines. Wildl Soc Bull 37: 66-74.

de Lucas M, Janss GFE \& Ferrer M (2004) The effects of a wind farm on birds in a migration point: the Strait of Gibraltar. Biodivers Conserv 13: 395-407.

Dennhardt AJ, Duerr AE, Brandes D \& Katzner TE (2015) Modeling autumn migration of a rare soaring raptor identifies new movement corridors in central Appalachia. Ecol Model 303: 19-29.

Dias MP, Granadeiro JP, Phillips RA, Alonso H \& Catry P (2011) Breaking the routine: individual Cory's shearwaters shift winter destinations between hemispheres and across ocean basins. P R Soc B-Biol Sci 278: $1786-1793$.

Dias MP, Granadeiro JP \& Catry P (2012) Do seabirds differ from other migrants in their travel arrangements? On route strategies of Cory's shearwater during its trans-equatorial Journey. PLOS ONE 7: e49376.

Dixon A, Batbayar N \& Purev-Ochir G (2011) Autumn migration of an Amur Falcon Falco amurensis from Mongolia to the Indian Ocean tracked by satellite. Forktail 27: 81-84.

Dodge S, Bohrer G, Weinzierl R, Davidson SC, Kays R, Douglas D et al. (2013) The environmental-data automated track annotation (Env-DATA) system: linking animal tracks with environmental data. Mov Ecol 1: 3.

Drewitt AL \& Langston RHW (2006) Assessing the impacts of wind farms on birds. Ibis 148: 29-42.

Duerr AE, Miller TA, Lanzone M, Brandes D, Cooper J, O’Malley K et al. (2015) Flight response of slopesoaring birds to seasonal variation in thermal generation. Funct Ecol 29: 779-790.

Felicísimo ÁM, Muñoz J \& González-Solis J (2008) Ocean surface winds drive dynamics of transoceanic aerial movements. PLOS ONE, 3: e2928.

González-Solís J, Croxall JP, Oro D \& Ruiz X (2007) Trans-equatorial migration and mixing in the wintering areas of a pelagic seabird. Front Ecol Environ 5: 297-301.

González-Solís J, Felicísim, ÁM, Fox JW, Afanasyev V, Kolbeinsson Y \& Muñoz J (2009) Influence of sea surface winds on shearwater migration detours. Mar Ecol Prog Ser 391: 221-230.

Gwinner E (1996) Circadian and circannual programmes in avian migration. J Exp Biol 199: 39-48.

Hedenström A (1993) Migration by soaring or flapping flight in birds: The relative importance of energy cost and speed. Philos T R Soc B 342: 353-361.

Horvitz N, Sapir N, Liechti F, Avissar R, Mahrer I \& Nathan R (2014) The gliding speed of migrating birds: slow and safe or fast and risky? Ecol Lett 17: 670-679.

Javed S, Douglas DC, Khan S, Shah JN \& Al Hammadi AA (2012) First description of autumn migration of Sooty Falcon Falco concolor from the United Arab Emirates to Madagascar using satellite telemetry. Bird Conserv Int 22: 106-119.

Katzner TE, Turk PJ, Duerr AE, Miller TA, Lanzone MJ, Cooper JL et al. (2015) Use of multiple modes of flight subsidy by a soaring terrestrial bird, the golden eagle Aquila chrysaetos, when on migration. J R Soc Interface 12: 0150530.

Kays R, Crofoot MC, Jetz W \& Wikelski M (2015) Terrestrial animal tracking as an eye on life and planet. Science 348: aaa2478.

Kemp MU, Shamoun-Baranes J, van Loon EE, McLaren JD, Dokter AM \& Bouten W (2012) Quantifying flowassistance and implications for movement research. J Theor Biol 308: 56-67. 
Kerlinger P (1985) Water-crossing behavior of raptors during migration. Wilson Bull 97: 109-113.

Kerlinger P (1989) Flight strategies of migrating hawks. University of Chicago Press, Chicago.

Kerlinger P \& Gauthreaux Jr SA (1985) Seasonal timing, geographic distribution, and flight behavior of Broad-winged Hawks during spring migration in south Texas: a radar and visual study. Auk 102: 735-743.

Kranstauber B, Weinzierl R, Wikelski M \& Safi K (2015) Global aerial flyways allow efficient travelling. Ecol Lett 18: 1338-1345.

Kuvlesky WP, Brennan LA, Morrison ML, Boydston KK, Ballard BM \& Bryant FC (2007) Wind energy development and wildlife conservation: challenges and opportunities. J Wildl Manage 71: 2487-2498.

Lanzone MJ, Miller TA, Turk P, Brandes D, Halverson C, Maisonneuve C et al. (2012) Flight responses by a migratory soaring raptor to changing meteorological conditions. Biol Lett 8: 710-713.

Liechti F (2006) Birds: blowin' by the wind? J Ornithol 147: 202-211.

Liechti F \& Bruderer B (1998) The relevance of wind for optimal migration theory. J Avian Biol 29: $561-$ 568.

Limiñana R, Romero M, Mellone U \& Urios V (2013) Is there a different response to winds during migration between soaring and flapping raptors? An example with the Montagu's harrier and the lesser kestrel. Behav Ecol Sociobiol 67: 823-835.

MacLeod CJ, Adams J \& Lyver P (2008) At-sea distribution of satellite-tracked grey-faced petrels, Pterodroma macroptera gouldi, captured on the Ruamaahua (Aldermen) Islands, New Zealand. Pap Proc R Soc Tasman 142: 73-88.

Madders M \& Whitfield DP (2006) Upland raptors and the assessment of wind farm impacts. Ibis 148: 43-56.

Mallon JM, Bildstein KL \& Katzner TE (2015) In-flight turbulence benefits soaring birds. Auk 133: 79-85.

Mandel JT, Bildstein KL, Bohrer G \& Winkler DW (2008) Movement ecology of migration in turkey vultures. P Natl Acad Sci USA 105: 19102-19107.

Mateos M \& Arroyo G (2011) Ocean surface winds drive local-scale movements within long-distance migrations of seabirds. Mar Biol 158: 329-339.

Mellone U, López-López P, Limiñana R \& Urios V (2011) Weather conditions promote route flexibility during open ocean crossing in a long-distance migratory raptor. Int J Biometeorol 55: 463-468.

Mellone U, Klaassen RHG, García-Ripollés C, Limiñana R, López-López P, Pavón D et al. (2012) Interspecific comparison of the performance of soaring migrants in relation to morphology, meteorological conditions and migration strategies. PLOS ONE 7: e39833.

Mellone U, De La Puente J, López-López P, Limiñana R, Bermejo A \& Urios V (2013) Migration routes and wintering areas of Booted Eagles Aquila pennata breeding in Spain. Bird Study 60: 409-413.

Mellone U, De La Puente J, López-López P, Limiñana R, Bermejo A \& Urios V (2015) Seasonal differences in migration patterns of a soaring bird in relation to environmental conditions: a multi-scale approach. Behav Ecol Sociobiol 69: 75-82.

Meyer S, Spaar R \& Bruderer B (2000) To cross the sea or to follow the coast? Flight directions and behaviour of migrating raptors approaching the Mediterranean Sea in autumn. Behaviour 137: 379-399.

Newton I (2008) The migration ecology of birds. Academic Press, London.

Nourani E, Yamaguchi NM, Manda A \& Higuchi H (2016) Wind conditions facilitate the seasonal watercrossing behaviour of Oriental Honey-buzzards Pernis ptilorhynchus over the East China Sea. Ibis 158: 506-518.

Pennycuick CJ (1982) The flight of petrels and albatrosses (Procellariiformes), observed in South Georgia and its vicinity. Philos T R Soc B 300: 75-106.

Pennycuick CJ (1998) Field observations of thermals and thermal streets, and the theory of cross-country soaring flight. J Avian Biol 29: 33-43.

Pennycuick CJ (2002) Gust soaring as a basis for the flight of petrels and albatrosses (Procellariiformes). Avian Sci 2: 1-12.

Phalan B, Phillips RA, Silk JR, Afanasyev V, Fukuda A, Fox J et al. (2007) Foraging behaviour of four albatross species by night and day. Mar Ecol Prog Ser 340: 271-286.

Richardson PL (2011) How do albatrosses fly around the world without flapping their wings? Prog Oceanogr 88: 46-58.

Richardson PL (2015) Upwind dynamic soaring of albatrosses and UAVs. Prog Oceanogr 130: 146-156.

Richardson WJ (1976) Autumn migration over Puerto Rico and the western Atlantic: A radar study. Ibis 118: 309-332.

Richardson WJ (1978) Timing and amount of bird migration in relation to weather: A review. Oikos 30: $224-272$.

Richardson WJ (1990a) Wind and orientation of migrating birds: A review. Experientia 46: 416-425.

Richardson WJ (1990b) Timing of bird migration in relation to weather: updated review. In: Gwinner E (ed) Bird Migration. pp 78-101. Springer Verlag, Berlin.

Richardson WJ (1991) Wind and orientation of migrat- 
ing birds: A review. In: Berthold P (ed) Orientation in Birds. pp 226-249. Birkhäuser, Basel.

Robinson WD, Bowlin MS, Bisson I, Shamoun-Baranes J, Thorup K, Diehl RH et al. (2010) Integrating concepts and technologies to advance the study of bird migration. Front Ecol Environ 8: 354-361.

Sachs G (2005) Minimum shear wind strength required for dynamic soaring of albatrosses. Ibis 147: 1-10.

Sachs G, Traugott J, Nesterova AP, Dell'Omo G, Kümmeth F, Heidrich W et al. (2012) Flying at no mechanical energy cost: disclosing the secret of wandering albatrosses. PLOS ONE 7: e41449.

Sapir N, Horvitz N, Wikelski M, Avissar R, Mahrer Y \& Nathan R (2011) Migration by soaring or flapping: numerical atmospheric simulations reveal that turbulence kinetic energy dictates bee-eater flight mode. $\mathrm{P}$ R Soc B-Biol Sci 278: 3380-3386.

Shaffer SA, Tremblay Y, Weimerskirch H, Scott D, Thompson DR, Sagar PM et al. (2006) Migratory shearwaters integrate oceanic resources across the Pacific Ocean in an endless summer. P Natl Acad Sci USA 103: 12799-12802.

Shamoun-Baranes J, Leshem Y, Yom-Tov Y \& Liechti O (2003a) Differential use of thermal convection by soaring birds over central Israel. Condor 105: 208 218.

Shamoun-Baranes J, Baharad A, Alpert P, Berthold P, Yom-Tov Y, Dvir Y et al. (2003b) The effect of wind, season and latitude on the migration speed of White Storks Ciconia ciconia, along the eastern migration route. J Avian Biol 34: 97-104.

Shamoun-Baranes J, Van Loon E, Alon D, Alpert P, Yom-Tov Y \& Leshem Y (2006) Is there a connection between weather at departure sites, onset of migration and timing of soaring-bird autumn migration in Israel? Glob Ecol Biogeogr 15: 541-552.

Smith NG, Goldstein DL \& Bartholomew GA (1986) Is long-distance migration possible for soaring hawks using only stored fat? Auk 103: 607-611.

Spaar R (1997) Flight strategies of migrating raptors; a comparative study of interspecific variation in flight characteristics. Ibis 139: 523-535.

Spaar R \& Bruderer B (1997) Migration by flapping or soaring: Flight strategies of Marsh, Montagu's and Pallid Harriers in southern Israel. Condor 458-469.

Spear LB \& Ainley DG (1997a) Flight speed of seabirds in relation to wind speed and direction. Ibis 139: 234-251.

Spear LB \& Ainley DG (1997b) Flight behaviour of seabirds in relation to wind direction and wing morphology. Ibis 139: 221-233.

Spear LB \& Ainley DG (1999) Migration routes of sooty shearwaters in the Pacific Ocean. Condor 101:
205-218.

Sullivan PP, Edson JB, Hristov T \& McWilliams JC (2008) Large-eddy simulations and observations of atmospheric marine boundary layers above nonequilibrium surface waves. J Atmos Sci 65: 1225-1245.

Thorne LH, Conners MG, Hazen EL, Bograd SJ, Antolos M, Costa DP et al. (2016) Effects of El Niño-driven changes in wind patterns on North Pacific albatrosses. J R Soc Interface 13: 20160196.

Thorup K, Alerstam T, Hake M \& Kjellén N (2003) Bird orientation: compensation for wind drift in migrating raptors is age dependent. P R Soc B-Biol Sci 270: S8-S11.

van Loon EE, Shamoun-Baranes J, Bouten W \& Davis SL (2011) Understanding soaring bird migration through interactions and decisions at the individual level. J Theor Biol 270: 112-126.

Vansteelant WMG, Verhelst B, Shamoun-Baranes J, Bouten W, van Loon EE \& Bildstein KL (2014) Effect of wind, thermal convection, and variation in flight strategies on the daily rhythm and flight paths of migrating raptors at Georgia's Black Sea coast. J Field Ornithol 85: 40-55.

Vansteelant WMG, Bouten W, Klaassen RHG, Koks BJ, Schlaich AE, van Diermen J et al. (2015) Regional and seasonal flight speeds of soaring migrants and the role of weather conditions at hourly and daily scales. J Avian Biol 46: 25-39.

Vansteelant WMG, Shamoun-Baranes J, van Manen, W, van Diermen, J \& Bouten, W (in press) Seasonal detours by soaring migrants shaped by wind regimes along the East Atlantic flyway. J Anim Ecol.

Villegas-Patraca R, Cabrera-Cruz SA \& Herrera-Alsina L (2014) Soaring migratory birds avoid wind farm in the Isthmus of Tehuantepec, southern Mexico. PLOS ONE 9: e92462.

Watanabe YY (2016) Flight mode affects allometry of migration range in birds. Ecol Lett 19: 907-914.

Weimerskirch H, Guionnet T, Martin J, Shaffer SA \& Costa DP (2000) Fast and fuel efficient? Optimal use of wind by flying albatrosses. P R Soc B-Biol Sci 267: 1869-1874.

Weimerskirch H, Chastel O, Barbraud C \& Tostain O (2003) Flight performance: frigatebirds ride high on thermals. Nature 421: 333-334.

Weimerskirch H, Louzao M, de Grissac S \& Delord K (2012) Changes in wind pattern alter albatross distribution and life-history traits. Science 335: 211-214.

Weimerskirch H, Delord K, Guitteaud A, Phillips RA \& Pinet P (2015) Extreme variation in migration strategies between and within wandering albatross populations during their sabbatical year, and their fitness consequences. Sci Rep 5: 8853. 
Weimerskirch H, Bishop C, Jeanniard-du-Dot T, Prudor A \& Sachs G (2016) Frigate birds track atmospheric conditions over months-long transoceanic flights. Science 353: 74-78.

Yamaguchi N, Arisawa Y, Shimada Y \& Higuchi H (2012) Real-time weather analysis reveals the adapt- ability of direct sea-crossing by raptors. J Ethol 30: $1-10$.

Yates RE, McClelland BR, McClelland PT, Key CH \& Bennetts RE (2001) The influence of weather on Golden Eagle migration in northwestern Montana. J Raptor Res 35: 81-90. 